\title{
Medical treatment for reflux oesophagitis does not consistently improve asthma control: a systematic review
}

\author{
J L Coughlan, P G Gibson, R L Henry
}

\begin{abstract}
Background-A systematic literature review was conducted to assess the effect of treating reflux oesophagitis on asthma outcomes.

Methods-Randomised controlled trials of reflux oesophagitis treatment in adults or children that reported asthma health outcomes were included and assessed in accordance with the standard Cochrane systematic review process. Patients were typically adults with asthma and concurrent symptomatic gastro-oesophageal reflux who received interventions that included pharmacological therapy, conservative management, and surgery. The following outcome measures were assessed: lung function, peak expiratory flow, asthma symptoms, asthma medications, and nocturnal asthma.
\end{abstract}

Results-From 22 potentially relevant published and unpublished randomised controlled trials, 12 were included. Treatment duration ranged from 1 week to 6 months. Eight trials reported that treatment improved at least one asthma outcome, but these outcomes differed between trials. Overall, treatment of reflux oesophagitis did not consistently improve forced expiratory volume in one second $\left(\mathrm{FEV}_{1}\right)$, peak expiratory flow rate, asthma symptoms, nocturnal asthma symptoms, or use of asthma medications in asthmatic subjects. Significant improvement in wheeze was reported in two studies.

Conclusions-The published literature does not consistently support treatment of reflux oesophagitis as a means of controlling asthma. Further large randomised controlled trials in subjects with a demonstrated temporal relationship between gastro-oesophageal reflux and asthma are needed. These trials should be conducted over at least 6 months to allow adequate time to observe a treatment effect.

(Thorax 2001;56:198-204)

Keywords: asthma; gastro-oesophageal reflux; systematic review

Correspondence to: Dr P G Gibson

mdpgg@mail.newcastle.edu.au

Received 8 February 2000 Returned to authors 10 April 2000

Revised version received

14 October 2000

Accepted for publication

20 November 2000 logical event that occurs mainly after meals in healthy people. Abnormal reflux is defined as significant acid exposure $(\mathrm{pH}<4.0)$ to the distal oesophagus for more than 1.2 hours (cumulative time $>5 \%$ ) over a 24 hour period as established by intra-oesophageal $\mathrm{pH}$ monitoring. ${ }^{56}$ Mechanisms by which oesophageal reflux may trigger asthma include acid aspiration, ${ }^{78}$ direct acid stimulation of the oesophagus, or stimulation of vagal nerves which heightens bronchial responsiveness to extrinsic allergens. $^{910}$

Clinicians are advised to elucidate gastrooesophageal reflux as a potential trigger in asthma and when gastro-oesophageal reflux is present, to consider treatment to improve asthma control. ${ }^{41}$ There are several approaches to treating gastro-oesophageal reflux: conservative anti-reflux measures; $\mathrm{H}_{2}$ antagonists either in standard dose or high dose; proton pump inhibitors; cisapride; and surgery including Nissen fundoplication and partial posterior hemi-fundoplication (Toupet and Lind techniques). Narrative reviews have identified that randomised trials have been conducted on each form of treatment with conflicting results. ${ }^{12-15}$ We have conducted a systematic review of the literature and metaanalysis to establish whether treatment of gastro-oesophageal reflux has beneficial effects on asthma outcomes.

\section{Methods}

This paper reports the results from a systematic review produced for the Cochrane Airways Group in $1998^{16}$ that has been updated for this publication. A protocol was developed, reviewed by the Cochrane Airways Group, and published on the Cochrane database of systematic reviews prior to conducting the review. All randomised controlled trials of gastrooesophageal reflux therapy published in any language and which reported at least one relevant asthma health outcome were included.

\section{IDENTIFICATION OF RELEVANT STUDIES}

An electronic search was undertaken of the Cochrane controlled clinical trials register (CCTR/Central) for papers published between the years 1966 and April 2000. The register is a combination of Medline, Embase, CINAHL, hand searched journals, and abstracts of meetings. The Cochrane Airways Groups clinical trials register was also searched and pharmaceutical companies were contacted to obtain results of unpublished trials. The following search strategy was employed: "asthma" or 
Table 1 Characteristics of included studies

\begin{tabular}{|c|c|c|c|c|c|c|}
\hline Study & Quality* & Type & $\begin{array}{l}\text { No enrolled/ } \\
\text { completed }\end{array}$ & Treatment & Dose/day & $\begin{array}{l}\text { Duration } \\
\text { (weeks) }\end{array}$ \\
\hline Ekstrom $^{19}$ & A7 & Crossover & $50 / 48$ & Ranitidine & $300 \mathrm{mg}$ & 4 \\
\hline Ford $^{20}$ & A6 & Crossover & $11 / 10$ & Omeprazole & $20 \mathrm{mg}$ & 4 \\
\hline Goodall $^{21}$ & A6 & Crossover & $20 / 18$ & Cimetidine & $1000 \mathrm{mg}$ & 6 \\
\hline Gustafsson $^{22}$ & A7 & Crossover & $40 / 37$ & Ranitidine & 150 or $300 \mathrm{mg}$ & 4 \\
\hline Kjellen $^{23}$ & $\mathrm{C} 4$ & Parallel & NA/62 & Conservative & & 8 \\
\hline Larrain $^{24}$ & A7 & Parallel & $90 / 81$ & $\begin{array}{l}\text { Cimetidine or } \\
\text { surgery }\end{array}$ & $1200 \mathrm{mg}$ & 26 \\
\hline Meier $^{25}$ & A7 & Crossover & $15 / 15$ & Omeprazole & $40 \mathrm{mg}$ & 6 \\
\hline Nagel $^{26}$ & B6 & Crossover & $15 / 14$ & Ranitidine & $450 \mathrm{mg}$ & 1 \\
\hline Teichtahl $^{27}$ & B6 & Crossover & $25 / 20$ & Omeprazole & $40 \mathrm{mg}$ & 4 \\
\hline Boeree $^{28}$ & B7 & Parallel & $36 / 30$ & Omeprazole & $80 \mathrm{mg}$ & 12 \\
\hline Levin $^{29}$ & B7 & Crossover & $11 / 9$ & Omeprazole & $80 \mathrm{mg}$ & 8 \\
\hline Kiljander $^{30}$ & B7 & Crossover & $57 / 52$ & Omeprazole & $80 \mathrm{mg}$ & 8 \\
\hline
\end{tabular}

${ }^{\star}$ Letters indicate whether the method of allocation to treatment groups was: $\mathrm{A}=$ adequate; $\mathrm{B}=$ unclear; $\mathrm{C}=$ inadequate. Numbers are Jadad scores from 1 to 7 where higher numbers indicate less opportunity for bias.

$\mathrm{NA}=$ not available.

"wheez ${ }^{\star}$ " and "gastro-oesophageal reflux" or "gastro-esophageal reflux" or "reflux" or "ger" or "gerd" or "acid" or "oesophagus" or "gastrooesophageal reflux" and "cimetidine" or "ranitidine" or "famotidine" or "nizatidine" or "omeprazole" or "pantoprazole" or "lansoprazole" or "surgery" or "Nissen". The titles, abstracts, and keywords of identified articles were screened for relevance and the reference lists of relevant articles were hand searched for additional articles. The authors of included studies were contacted in order to identify any additional published or unpublished studies. We included randomised controlled trials and controlled studies of any gastro-oesophageal reflux treatment in patients with asthma.

ASSESSMENT OF VALIDITY

To minimise bias, two reviewers independently assessed the full text version of the trials for inclusion/exclusion, methodological quality, and data extraction using standardised forms. The percentage agreement for inclusion/ exclusion was $100 \%$. Methodological quality was assessed using two instruments. The first, the Jadad system, ${ }^{17}$ scores the quality of the paper based on descriptions of inclusion criteria (1 point), randomisation (stated, and appropriate; 2 points), adverse effects (1 point), blinding (described and appropriate; 2 points), description of withdrawals and dropouts ( 1 point), and statistical analysis (1 point). Each criterion was scored and summed to give a maximum score of 8 . Studies were further assessed as "adequate", "inadequate", or "unclear" according to the actual methods used for randomisation and concealment of allocation. Authors were contacted to verify data and provide further information about methodological approaches and outcomes.

ANALYSIS

For continuous outcomes that were the same unit of measure, a weighted mean difference (WMD) and 95\% confidence interval was calculated. ${ }^{18}$ Fixed effects models were used and significance accepted at $\mathrm{p}<0.05$. For dichotomous outcomes the relative risk was calculated with $95 \%$ confidence intervals. The relative risk is the risk of experiencing an outcome when treated compared with the risk of experiencing that outcome if untreated. Values of $<1$ indicate a favourable treatment effect. Heterogeneity of the pooled trial results was calculated using a $\chi^{2}$ test with appropriate degrees of freedom. Where the heterogeneity exceeded the expected $90 \%$ level, the results were not pooled and subgroup analysis was carried out to try to explain the source of the heterogeneity.

Outcomes were analysed according to the type of intervention the subjects received-that is, medical or surgical treatment. Medical interventions were subgrouped according to the type of treatment: (1) $\mathrm{H}_{2}$ antagonist; (2) proton pump inhibitor; or (3) conservative treatment

\section{Results}

INCLUDED STUDIES

The search strategy yielded 259 abstracts of which 21 full text versions of papers and one abstract were retrieved. Of these, 12 randomised controlled trials ${ }^{19-30}$ were included. Nine were crossover trials and three used a parallel design. Four trials investigated $\mathrm{H}_{2}$ antagonists, ${ }^{19212226}$ six investigated proton pump inhibitors, ${ }^{20} 2527-30$ one assessed conservative treatment of gastro-oesophageal reflux, ${ }^{23}$ and one had three arms which included a surgical approach, an $\mathrm{H}_{2}$ antagonist, and a placebo control. ${ }^{24}$ The characteristics of the included studies are described in table 1 . Ten studies were excluded because the subjects did not have asthma, ${ }^{31-35}$ the trials were not randomised ${ }^{36}$ or not controlled, ${ }^{37}$ the interventions did not treat reflux, ${ }^{38} 39$ or the subjects did not have reflux. ${ }^{40}$

METHODOLOGICAL QUALITY

All studies were appropriately randomised except that by Kjellen et $a l^{3}$ which used alternation to allocate subjects into treatment or control groups. Nine of the 12 studies used blinded allocation procedures. The range of study quality ratings was $4-7$, the mode 7 and the mean 6.2 indicating only minimal opportunity for bias among these studies.

SUBJECT CHARACTERISTICS

Characteristics of the subjects are summarised in table 2. They were typically adults with symptomatic reflux. Asthma was diagnosed most commonly in accordance with the 


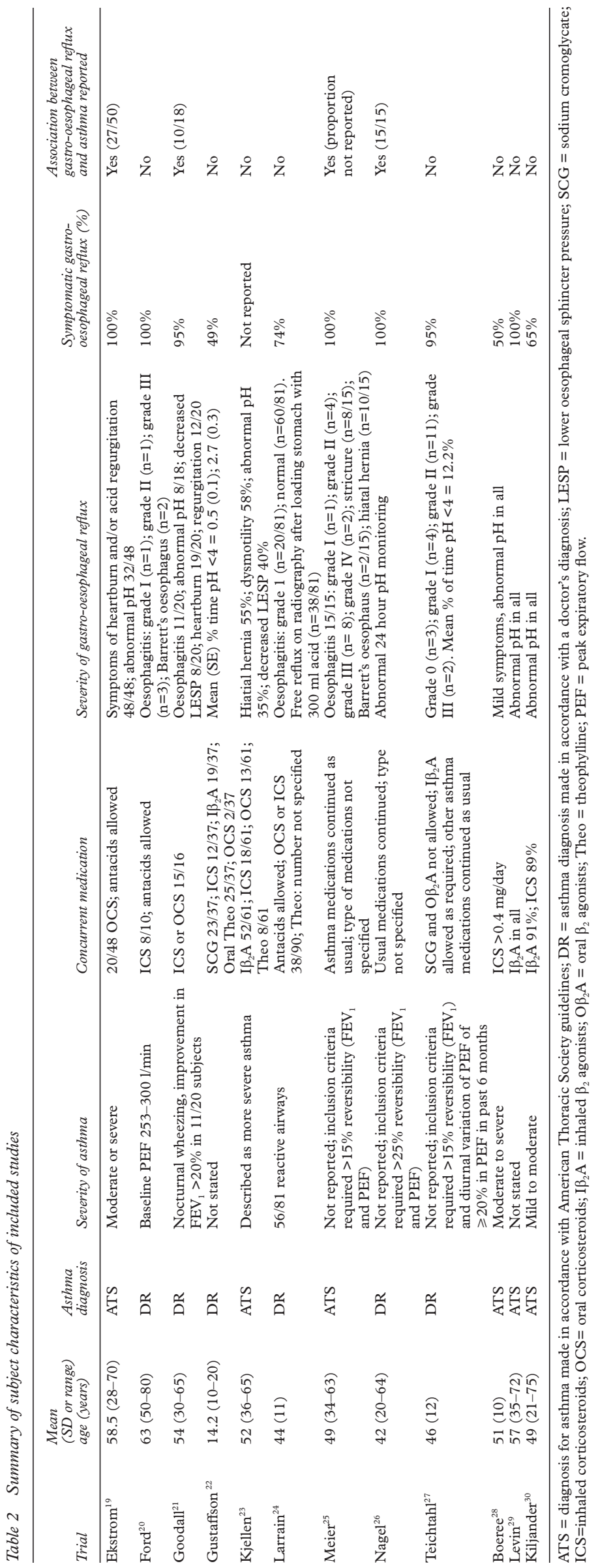

American Thoracic Society guidelines or a doctor's diagnosis. The severity of asthma varied from mild to severe. Gastro-oesophageal reflux was confirmed by one or more of the following methods: history of symptoms, endoscopy, manometry, acid perfusion test, 24 hour $\mathrm{pH}$ monitoring, and/or measurement of oesophageal motility. Reporting of gastrooesophageal reflux severity tended to be more explicit than reporting of asthma severity. A clinical relationship between asthma and gastro-oesophageal reflux was reported in four studies, ${ }^{19212526}$ one of which excluded subjects that could not demonstrate this relationship. ${ }^{26}$

OUTCOMES

Twelve randomised controlled trials investigated the treatment of gastro-oesophageal reflux on asthma in 432 subjects of whom 396 completed the studies. Asthma outcomes were reported inconsistently among the studies and this limited quantitative data synthesis (metaanalysis). No studies reported hospital admissions or emergency room visits resulting from asthma. The study results are summarised in table 3 .

LUNG FUNCTION

Overall, there was no clear and consistent benefit of anti-reflux treatment on lung function in asthmatic patients with gastro-oesophageal reflux. Ten trials of 11 interventions reported forced expiratory volume in one second $\left(\mathrm{FEV}_{1}\right)$. Of these, one omeprazole and one cimetidine intervention reported a small but significant improvement in $\mathrm{FEV}_{1}{ }^{24}{ }^{25}$ whereas the remaining studies found no benefit of gastro-oesophageal reflux treatment on $\mathrm{FEV}_{1}$.

An improvement in morning peak expiratory flow (PEF) was reported in only one of the six studies that reported this variable. ${ }^{29} \mathrm{~A}$ metaanalysis of these studies indicated no effect of anti-reflux therapy on morning peak flow (fig 1). A significant improvement in evening PEF, measured as percentage of predicted, was reported after treatment with omeprazole $40 \mathrm{mg} /$ day for 4 weeks $^{27}$ and after treatment with cimetidine $1000 \mathrm{mg} /$ day for 6 weeks. $^{21}$ However, no effect of treatment on evening PEF was reported in five other studies. ${ }^{19} 20262829$ Similarly, our unpaired analysis of three studies ${ }^{19-27}$ using the PEF end point in $1 /$ min showed no significant treatment effect on evening PEF (fig 2). Daytime PEF was not reported to be improved with treatment for reflux oesophagitis. ${ }^{20-22} 25$ Airway hyperresponsiveness was not affected by treatment with omeprazole ${ }^{27} 28$ or with an $\mathrm{H}_{2}$ antagonist. ${ }^{19}{ }^{22}$

SYMPTOMS

Asthma symptoms were measured and reported in all of the included studies but in so many different ways that a meaningful combination of the data was not possible.

Of the 12 trials, three reported a significant improvement in symptoms. Kjellen et $a l^{23}$ reported a significant reduction in the proportion of subjects experiencing respiratory symptoms including dyspnoea, cough, wheeze, and expectoration after conservative treatment 
Table 3 Summary of results of gastro-oesophageal reflux treatment on asthma outcomes

\begin{tabular}{|c|c|c|c|c|c|c|c|}
\hline Study & $F E V_{1}$ & $\begin{array}{l}\text { Morning } \\
\text { PEF }\end{array}$ & $\begin{array}{l}\text { Evening } \\
P E F\end{array}$ & $A H R$ & $\begin{array}{l}\text { Asthma } \\
\text { symptoms }\end{array}$ & $\begin{array}{l}\text { Nocturnal } \\
\text { symptoms }\end{array}$ & $\begin{array}{l}\text { Asthma } \\
\text { medications }\end{array}$ \\
\hline Ekstrom $^{19}$ & $\mathrm{NE}$ & NE & NE & NE & $\mathrm{NE}$ & + & + \\
\hline Ford $^{20}$ & NA & NE & NE & NA & $\mathrm{NE}$ & NE & $\mathrm{NE}$ \\
\hline Goodall $^{21}$ & $\mathrm{NE}$ & $\mathrm{NE}$ & + & NA & $\mathrm{NE}$ & + & $\mathrm{NE}$ \\
\hline Gustafsson $^{22}$ & $\mathrm{NE}$ & NA & NA & $\mathrm{NE}$ & $\mathrm{NE}$ & $\mathrm{NE}$ & NA \\
\hline Kjellen $^{23}$ & $\mathrm{NE}$ & NA & NA & NA & + & NA & + \\
\hline $\begin{array}{l}\text { Larrain }^{24} \\
\quad \text { (cimetidine) }^{\text {(cine }}\end{array}$ & + & NA & NA & NA & + & NA & + \\
\hline $\begin{array}{l}\text { Larrain }^{24} \\
\quad \text { (surgery) }\end{array}$ & $\mathrm{NE}$ & NA & NA & NA & + & NA & + \\
\hline Meier $^{25}$ & + & NA & NA & NA & $\mathrm{NE}$ & NA & $\mathrm{NE}$ \\
\hline Nagel $^{26}$ & NA & NE & NE & NA & NE & NA & NE \\
\hline Teichtahl $^{27}$ & NE & $\mathrm{NE}$ & + & $\mathrm{NE}$ & $\mathrm{NE}$ & NA & NA \\
\hline Boeree $^{28}$ & NE & $\mathrm{NE}$ & NE & NE & NE & NE & NA \\
\hline Levin $^{29}$ & $\mathrm{NE}$ & + & NE & NA & + & NA & NA \\
\hline Kiljander $^{30}$ & $\mathrm{NE}$ & $\mathrm{NE}$ & NA & NA & NE & + & $\mathrm{NE}$ \\
\hline
\end{tabular}

$+=$ significant treatment effect $(\mathrm{p}<0.05) ; \mathrm{NA}=$ data not available; $\mathrm{NE}=$ no significant treatment effect; $\mathrm{FEV}_{1}=$ forced expiratory flow in one second; $\mathrm{PEF}=$ peak expiratory flow; $\mathrm{AHR}=$ airway hyperresponsiveness.

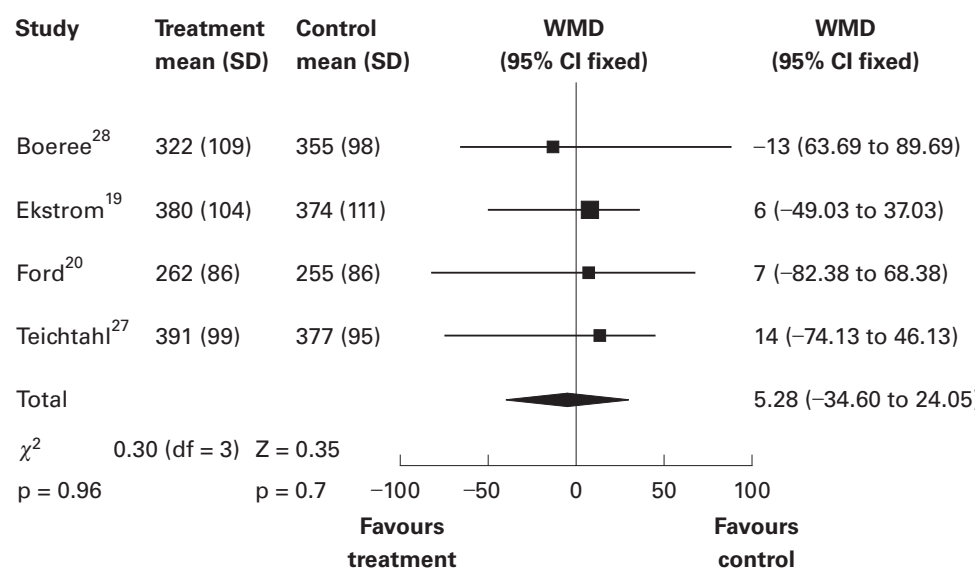

Figure 1 Effect of medical treatment for gastro-oesophageal reflux versus placebo on morning peak expiratory flow. Weighted mean difference (WMD) for individual trials. $\chi^{2}$ refers to test for heterogeneity across different trials. $Z$ is the test statistic for weighted mean difference. WMD for individual trials (area of the square proportional to amount of information contributed) and for total (diamond =WMD and 95\% CI). The convention of favourable results being displayed to the left hand side of null effect warrants negative signs being placed before results. Results are reported as l/min.

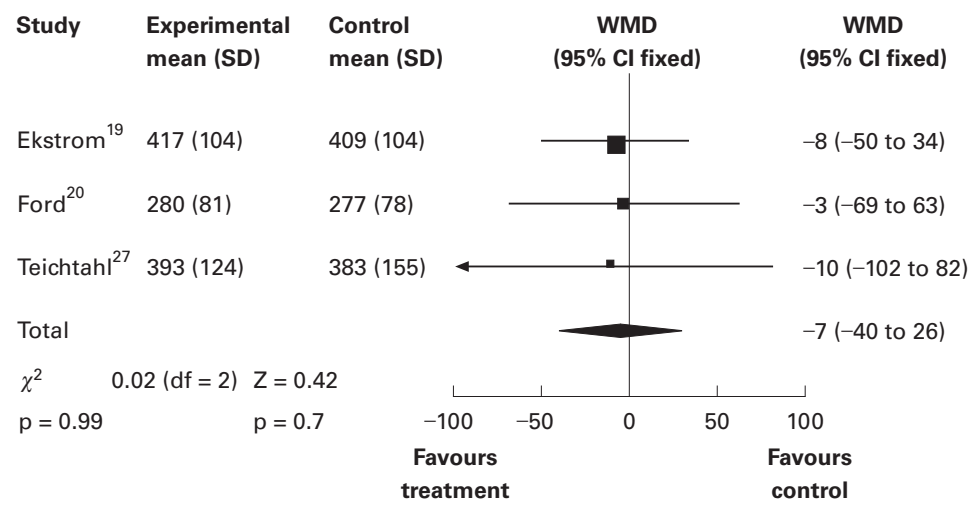

Figure 2 Effect of medical treatment for gastro-oesophageal reflux versus placebo on evening peak expiratory flow. Weighted mean difference (WMD) for individual trials. Results are reported as l/min.
6 months. Levin et $a l^{29}$ reported an improvement in asthma related quality of life with omeprazole. The remaining nine trials found no significant treatment benefit.

Three out of six studies which measured and reported nocturnal asthma symptoms found a treatment related improvement. Ekstrom et al ${ }^{19}$ reported a significant but clinically modest improvement in nocturnal asthma symptom scores after treatment with an $\mathrm{H}_{2}$ antagonist. In this study, subjects who had a history of reflux associated respiratory symptoms showed a greater improvement with ranitidine. Goodall et $a l^{1}$ also demonstrated a positive effect of an $\mathrm{H}_{2}$ antagonist on nocturnal asthma. Kiljander et $a l^{30}$ reported fewer nocturnal symptoms with high dose omeprazole, whereas Boeree et a ${ }^{28}$ found no such effect. Gustafsson et $a l^{2}$ reported significant positive correlations between the improvement in nocturnal, morning, and total asthma symptoms and the degree of pathological gastro-oesophageal reflux at oesophageal $\mathrm{pH}$ monitoring in children and adolescents. However, the overall results from Gustafsson et $a l^{22}$ and Ford et $a l^{20}$ did not demonstrate a benefit on nocturnal asthma symptoms from gastro-oesophageal reflux treatment (fig 3).

Three of seven studies reported a significant reduction in $\beta$ agonist use and this effect was greatest in those subjects who had a history of reflux associated respiratory symptoms. The reduction was from $5.9(0.92)$ to $5.2(0.88)$ puffs of $\beta_{2}$ agonist per day and is of doubtful clinical significance. Kjellen $e t a l^{23}$ also reported a significant reduction in the consumption of $\beta$-adrenergic sprays in the treatment group ( 4.4 to 3.8 doses/day). Larrain et $a l^{4}$ recorded a total medication score and found a significant reduction from baseline to follow up at 6 months in patients treated with cimetidine and those who underwent surgery, and a nonsignificant increase in the placebo group. Five other trials did not find a treatment related improvement in consumption of rescue medication 2021252630 despite having adequate power to do so.

GASTRO-OESOPHAGEAL REFLUX INDUCED ASTHMA Four studies identified subjects in whom reflux appeared to trigger asthma. In these subjects, although gastro-oesophageal reflux was temporally associated with asthma, ${ }^{19} 212526$ no consistent benefit of gastro-oesophageal reflux therapy was demonstrated on asthma outcomes (tables 2 and 3 ).

\section{EFFECT OF TREATMENT ON}

GASTRO-OESOPHAGEAL REFLUX

The effect of study treatment on gastrooesophageal reflux was reported in 11 of the 12 trials. Symptoms were assessed in 10 studies and study treatment improved reflux symptoms in only five of them. The effect of treatment on oesophageal $\mathrm{pH}$ was assessed in three studies and was improved by high dose omeprazole $^{28}$ and surgery ${ }^{24}$ but not by $\mathrm{H}_{2}$ antagonists $^{24}$ or by low dose omeprazole. ${ }^{27}$ 


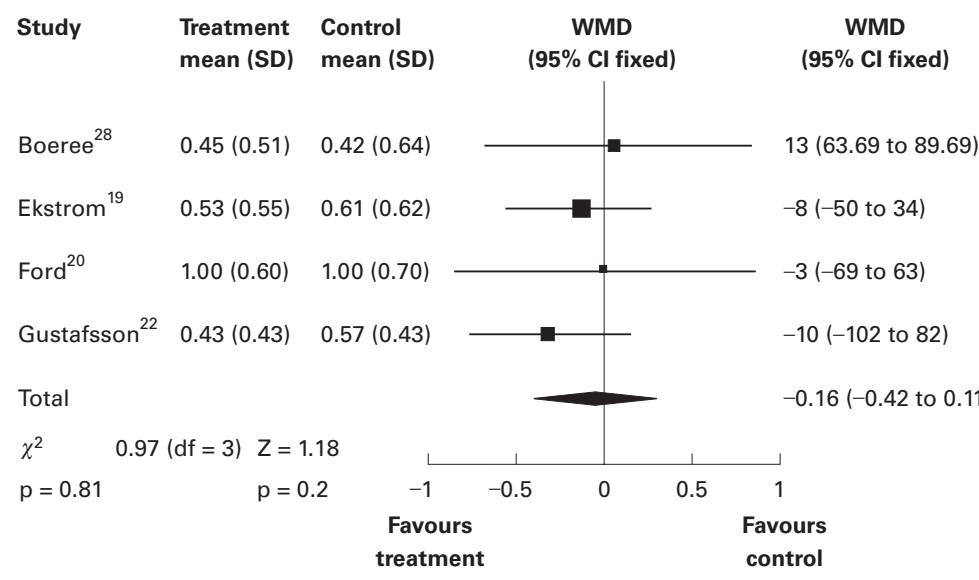

Figure 3 Effect of medical treatment for gastro-oesophageal reflux versus placebo on nocturnal asthma symptom scores. Standardised mean difference (SMD) for individual trials (area of the square proportional to amount of information contributed) and for total (diamond $=S M D$ and $95 \% C I$ ).

\section{Discussion}

In this systematic review of 12 randomised controlled clinical trials the treatment of gastro-oesophageal reflux did not reveal a consistent benefit on asthma. There was no clear effect on lung function, airway responsiveness, or asthma symptoms. Although nine of the 12 trials reported at least one significant outcome, there was no consistency in these effects.

In general, the participants in these studies were selected on the basis of having a diagnosis of asthma and gastro-oesophageal reflux. Gastro-oesophageal reflux was diagnosed by various methods including oesophageal $\mathrm{pH}$ monitoring (distal and proximal), endoscopy, history of symptoms, and acid perfusion test. Not all subjects had symptomatic gastrooesophageal reflux during the study period. Furthermore, a requirement to show that gastro-oesophageal reflux precipitated asthma was an entry criterion in only two studies..$^{25}$ $\mathrm{FEV}_{1}$ improved in one of these studies but other outcomes were negative. An association was found to be present in a subset of subjects in two further trials. Ekstrom et $a l^{19}$ reported an improvement in nocturnal asthma and use of rescue medications. Goodall et $a l^{21}$ also reported an improvement in nocturnal asthma symptoms and an improvement in evening PEF.

The lack of consistently convincing evidence among the randomised controlled trials contrasts with prior uncontrolled studies ${ }^{41}$ which reported a good response of gastrooesophageal reflux treatment in some asthmatic subjects. The underlying reasons for the inconsistent results are not clear. The effect of bias may have contributed to the different findings since non-randomised study designs have the potential to overestimate treatment effects. Non-publication of negative observational trials may be a further reason for the difference in findings between the two study designs. It is also interesting to compare our observations with those of Field and Sutherland who analysed combined data from multiple studies of anti-reflux therapy in asthma. ${ }^{42}$ Although they included all the studies that we did, they also used three trials with open design. ${ }^{3641}$ These three uncontrolled studies all had positive outcomes with reduced asthma symptoms (all three studies), less medication use (one study), and improved spirometric parameters (one study). Their overall conclusion from analysis of their combined data was favourable, reinforcing the belief that inclusion of studies with poor quality design will overestimate the benefits of treatment.

We found an insufficient sample size in the pooled studies to detect a clinically significant treatment effect in PEF. It is therefore possible that current studies are negative because of a type 2 error. Using the estimates of sample variance from the meta-analysis of PEF data, a sample size of 506 subjects would be required to detect a difference in PEF of $201 / \mathrm{min}$ with $\alpha$ at 0.05 and power of $80 \%$. The pooled sample size of studies reporting evening PEF as an outcome was 184 (fig 1). The review by Field and Sutherland ${ }^{42}$ also concluded that medical anti-reflux treatment has minimal or no effect on lung function.

The duration of drug treatment used in the studies included in our systematic review was often short. It might be argued that a longer period of treatment would be necessary before improved control of gastro-oesophageal reflux resulted in benefits for asthma. Indeed, when treatment was given for 6 months, ${ }^{24}$ asthma symptoms and use of medications were improved. Studies consistently averaged the results over the entire treatment period for symptom scores, PEF, and medication use. If the effect of treatment was delayed or required time to be manifest, then averaging results over the entire treatment period would bias against finding a treatment effect. The likely implication is that these studies might underestimate the response to gastro-oesophageal reflux therapy.

Our original intention had been to look at the effect of treatment of gastro-oesophageal reflux in both adults and children with asthma. The paucity of appropriate paediatric studies limited the scope of the final review, with the study by Gustafsson et $a l^{2}$ being the only randomised controlled trial to include children (age range for patients in this study 10-20 years, mean age 14.2 years). There is therefore no way of determining whether the observations made in this systematic review are generalisable to children with asthma and gastrooesophageal reflux.

The relationships between asthma and gastro-oesophageal reflux have been well recognised. Both conditions are common and would be expected to coexist, purely on the basis of chance. Studies in children ${ }^{23}$ and adults ${ }^{1}$ have found a high prevalence of gastrooesophageal reflux in patients with asthma, which suggests that the relationship may be causal rather than casual. A number of mechanisms could explain how gastro-oesophageal reflux would trigger asthma. Aspiration of gastric contents into the airways is an obvious possibility. Similarly, acid stimulation of vagal nerve fibres in the mid oesophagus can result in wheeze. On the other hand, the large swings in intrathoracic pressure associated with acute 
exacerbations of asthma might result in asthma promoting reflux. Clinical observation suggests that there are individuals in whom gastrooesophageal reflux is an important trigger to asthma. However, it is unclear whether or not this is a common phenomenon.

Medical treatment of gastro-oesophageal reflux for asthma relies on the assumption that it is the acidity of the refluxed material that induces respiratory symptoms, not the presence of the material (acidic or not) in the lower oesophagus. It is not clear if those individuals who respond to treatment do so because of an improvement in lower oesophageal $\mathrm{pH}$ and a consequent reduction in oesophagitis, or because of a reduction in the quantity of refluxed material into the lower oesophagus, or both. There appears to be little evidence to indicate that acid perfusion has a significant adverse effect on lung function. ${ }^{44}$ To have the greatest chance of finding an improvement in asthma symptoms and lung function, the treatment needs to be effective in controlling reflux as well as reducing acidity. This review found a variety of treatments for reflux, with surgical, medical and non-pharmacological therapies. An obvious question to ask is whether the therapies used were successful in treating the reflux and/or the reflux oesophagitis. This was only objectively confirmed in two studies using high dose omeprazole ${ }^{28}$ and surgery. ${ }^{24}$ An optimal study design would establish that the reflux oesophagitis was adequately treated as a prerequisite to an assessment of the effect on the asthma.

Future research is warranted to examine the effects of treatment for gastro-oesophageal reflux on asthma control. A parallel group, randomised, placebo controlled trial with a surgical arm versus high dose proton pump inhibitor for up to 6 months would be appropriate. Subjects with symptomatic asthma and symptomatic gastro-oesophageal reflux in whom gastro-oesophageal reflux was shown to precipitate episodes of asthma should be studied, with assessment of day and night asthma symptoms, quality of life, lung function, and PEF, and an assessment of the effects of treatment on gastro-oesophageal reflux. The data should be evaluated as change from baseline, or data during the last few weeks of treatment should be compared between groups. A large sample size would be required, and pooled variance estimates from this review indicate the need to include 250 subjects in each treatment arm.

In conclusion, control of asthma was not consistently improved when asthmatic subjects were treated for gastro-oesophageal reflux. A subgroup of patients were reported to gain benefit but it appears difficult to predict responders. An improvement in symptoms was more likely to be observed than an improvement in lung function. At present it is not possible to recommend the general application of medical treatment of reflux oesophagitis as a means of controlling asthma. Further research is required in selected subgroups treated either surgically or medically for a prolonged period.
The authors would like to thank NSW Health and National Asthma Campaign for their financial and administrative support
respectively. We would also like to thank Dr T Ekstrom, Dr P M Gustafsson, Dr A Larrain, and Dr H Teichtahl for responding to our request for further information about their studies.

1 Sontag S, O'Connell S, Khandelwal S, et al. Most asthmatics have gastroesophageal reflux with or without bronchodilator therapy. Alimentary Tract 1990;99:613-20.

2 Martin M, Grunstein M, Larsen G. The relationship of gastroesophageal reflux to nocturnal wheezing in children with asthma. Ann Allergy 1982;49:318-22.

3 Tucci F, Resti M, Fontana R, et al. Gastroesophageal reflux and bronchial asthma: prevalence and effect of cisapride therapy. F Pediatr Gastroenterol Nutr 1993;17:265-70.

therapy. F Pediatr Gastroenterol Nutr 1993;17:265-70.
4 Anonymous. Australian asthma management handbook. Anonymous. Australian asthma management

5 Johnson L, DeMeester T. Twenty-four hour pH monitoring of the distal oesophagus: a quantitative measure of gastroesophageal reflux. Am f Gastroenterol 1974;62:325-30.

6 Johnsson F, Joelsson B, Isberg P-E. Ambulatory 24 hour intraesophageal $\mathrm{pH}$-monitoring in the diagnosis of gastroesophageal reflux disease. Gut 1987;28:1145-50.

7 Klotz S, Moeller R. Hiatal hernia and intractable bronchial asthma. Ann Allergy 1971;29:325-8.

8 Mays E. Intrinsic asthma in adults: association with gastroesophageal reflux. FAMA 1976;236:2626-8.

9 Mansfield I. Gastro-oesophageal reflux and respiratory disorders: a review. Ann Allergy 1989;62:158-63.

10 Tuchman D, Boyle J, Pack I. Comparison of airway responses following tracheal or oesophageal acidification in responses following tracheal or oesophage
the cat. Gastroenterology 1984;87:872-81.

11 Barnes P, Woolcock A. Difficult asthma. Eur Respir 7 1998; 12:1209-18.

12 Winter D, Brennan N, O'Sullivan G. Reflux induced respiratory disorders (RIRD). $\mathcal{F}$ Irish Coll Phys Surg 1997;26: 202-10.

13 Choy D, Leung R. Gastro-oesophageal reflux disease and asthma. Respirology 1997;2:163-8.

14 Kahrilas P. Gastroesophageal reflux disease. FAMA 1996; 276:983-8.

15 Simpson W. Gastroesophageal reflux disease and asthma. Arch Intern Med 1995;155:798-803.

16 Gibson P, Henry R, Coughlan J. Gastro-oesophageal reflux treatment for asthma in adults and children. The Cochrane Library, Issue 1, 2000. Oxford Update Software.

17 Moher D, Jadad AR, Nichol, G, et al. Assessing the quality of randomised controlled trials: an annotated bibliography of scales and check lists. Control Clin Trials 1995;16:62-73.

18 Bracken M. Statistical methods for analysis of effects of treatment in overviews of randomized trials. In: Sinclair J, Bracken M, eds. Effective care of the newborn infant. Oxford: Oxford Unversity Press, 1992:13-8.

19 Ekstrom T, Lindgren B, Tibbling L. Effects of ranitidine treatment on patients with asthma and a history of gastroesophageal reflux: a double blind crossover study. Thorax 1989;44:12-23.

20 Ford G, Oliver P, Prior J, et al. Omeprazole in the treatment of asthmatics with nocturnal symptoms and gastrooesophageal reflux: a placebo-controlled cross-over study. Postgrad Med f 1994;70:350-4.

21 Goodall R, Earis J, Cooper D, et al. Relationship between asthma and gastro-oesophageal reflux. Thorax 1981;36: 116-21.

22 Gustafsson P, Kjellerman N, Tibbling L. A trial of ranitidine in asthmatic children and adolescents with or without pathological gastro-oesophageal reflux. Eur Respir $\mathcal{f} 1992$; pathological $201-6$.

23 Kjellen G, Tibbling L, Wranne B. Effect of conservative treatment of oesophageal dysfunction on bronchial asthma. Eur F Respir Dis 1981;62:190-7

24 Larrain A, Carrasco E, Galleguillos F, et al. Medical and surgical treatment of non-allergic asthma associated with gastroesophageal reflux. Chest 1991;99:1330-5.

25 Meier J, McNally P, Punja M, et al. Does omeprazole (Prilosec) improve respiratory function in asthmatics with gastroesophageal reflux? Dig Dis Sci 1994;39:2127-33.

26 Nagel R, Brown P, Perks W, et al. Ambulatory pH monitoring of gastro-esophageal reflux in 'morning dipper' asthmatics. BMf 1988;297:1371-3.

27 Teichtahl H, Kronborg I, Yeomans N, et al. Adult asthma and gastro-oesophageal reflux: the effects of omeprazole therapy on asthma. Aust NZ f Med 1996;26:671-6.

28 Boeree MJ, Peters FTM, Postma DS, et al. No effects of high-dose omeprazole in patients with severe airway hyper-
responsiveness and (a)symptomatic gastro-oesophageal responsiveness and (a)symptomatic
reflux. Eur Respir F 1998;11:1070-4.

29 Levin TR, Sperling RM, McQuaid KR. Omeprazole improves peak expiratory flow rate and quality of life in asthmatics with gastro-oesophageal reflux. Am $\mathcal{F}$ Gastroenterol 1998,93:1060-3.

30 Kiljander TO, Salomaa ERM, Hietanen EK, et al. Gastroesophageal reflux in asthmatics. A double blind, placebo controlled crossover study with omeprazole. Chest 1999; 116:1257-64.

31 Cloud M, Offen W, Hill EA. Nizatidine versus placebo in gastro-oesophageal reflux disease: a 6-week, multicentre, randomised, double-blind comparison. Br f Clin Pharmacol Supplement 1994;48:11-19.

32 Langer J, Winthrop A, Issenman R. The single-subject randomised trial: a useful clinical tool for assessing therapeutic efficacy in $654-7$. 
33 Laursen L, Haveund T, Bondesen S, et al. Omeprazole in the long-term treatment of gastro-oesophageal reflux disease: a double-blind randomized dose-finding study (unpublished).

34 Spechler S. Comparison of medical and surgical therapy for complicated gastroesophageal reflux disease in veterans. $N$ Engl f Med 1992;326:786-92.

35 Spechler S, Gordon D, Cohen J, et al. The effects of antireflux therapy on pulmonary function in patients with sever gastroesophageal reflux disease. Am $\mathcal{F}$ Gastroenterol 1995 90:915-7.

36 Harper P, Bergner A, Kaye M. Antireflux treatment for asthma. Arch Intern Med 1987;147:56-60.

37 Poder G, Bokay J, Parrak Z, et al. Occurrence of gastro-esophageal reflux and the efficiency of antireflux treatment in reactive airway diseases of children. Clin Invest - Mon Sci Monit 1997;3:485-8.

38 Hubert D, Gaudric M, Guerre J, et al. Effect of theophylline on gastroesophageal reflux in patients with asthma. $\mathcal{F}$ on gastroesophageal reflux in patients
39 Singh V, Jain N. Asthma as a cause for, rather than a result of, gastroesophageal reflux. F Asthma 1983;20:241-3.

40 Tashkin D, Ungerer R, Wolfe R, et al. Effect of orally administered cimetidine on histamine- and antigen-induced bronchospasm in subjects with asthma. Am Rev Respir Disease 1982;125:691-5.

41 Harding S, Richter J, Guzzo $M$, et al. Asthma and gastroesophageal reflux: acid suppressive therapy improves asthma outcome. Am f Med 1986;100:395-405.

42 Field S, Sutherland L. Does medical antireflux therapy improve asthma in asthmatics with gastroesophageal reflux? Chest 1998;114:275-83.

43 Andze G, Brandt M, St-Vil D, et al. Diagnosis and treatment of gastroesophageal reflux in 500 children with respiratory symptoms: the value of $\mathrm{pH}$ monitoring. 7 Pediatr Surg 1991;26:295-9.

44 Field S. A critical review of the studies of the effects of simulated or real gastroesophageal reflux on pulmonary function in asthmatic adults. Chest 1999;115:848-56. 